\title{
Hospital at Home: Feasibility and Outcomes of a Program To Provide Hospital-Level Care at Home for Acutely III Older Patients
}

Bruce Leff, MD; Lynda Burton, ScD; Scott L. Mader, MD; Bruce Naughton, MD; Jeffrey Burl, MD; Sharon K. Inouye, MD, MPH; William B. Greenough III, MD; Susan Guido, RN; Christopher Langston, PhD; Kevin D. Frick, PhD; Donald Steinwachs, PhD; and John R. Burton, MD

Background: Acutely ill older persons often experience adverse events when cared for in the acute care hospital.

Objective: To assess the clinical feasibility and efficacy of providing acute hospital-level care in a patient's home in a hospital at home.

Design: Prospective quasi-experiment.

Setting: 3 Medicare-managed care (Medicare + Choice) health systems at 2 sites and a Veterans Administration medical center.

Participants: 455 community-dwelling elderly patients who required admission to an acute care hospital for community-acquired pneumonia, exacerbation of chronic heart failure, exacerbation of chronic obstructive pulmonary disease, or cellulitis.

Intervention: Treatment in a hospital-at-home model of care that substitutes for treatment in an acute care hospital.

Measurements: Clinical process measures, standards of care, clinical complications, satisfaction with care, functional status, and costs of care.
Results: Hospital-at-home care was feasible and efficacious in delivering hospital-level care to patients at home. In 2 of 3 sites studied, $69 \%$ of patients who were offered hospital-at-home care chose it over acute hospital care; in the third site, $29 \%$ of patients chose hospital-at-home care. Although less procedurally oriented than acute hospital care, hospital-at-home care met quality standards at rates similar to those of acute hospital care. On an intention-to-treat basis, patients treated in hospital-at-home had a shorter length of stay (3.2 vs. 4.9 days) $(P=0.004)$, and there was some evidence that they also had fewer complications. The mean cost was lower for hospital-at-home care than for acute hospital care $(\$ 5081$ vs. $\$ 7480)(P<0.001)$.

Limitations: Possible selection bias because of the quasi-experimental design and missing data, modest sample size, and study site differences.

Conclusions: The hospital-at-home care model is feasible, safe, and efficacious for certain older patients with selected acute medical illnesses who require acute hospital-level care.

Ann Intern Med. 2005;143:798-808.

For author affiliations, see end of text.

www.annals.org to a pilot study of a physician-led substitutive hospital-athome model for older persons with acute medical illness (15). The aim of our study was to evaluate the safety, efficacy, clinical and functional outcomes, patient and caregiver satisfaction, and costs of providing acute hospitallevel care in a hospital at home that substituted entirely for admission to an acute care hospital for older persons.

\section{Methods}

Patients

The target sample was community-dwelling persons, age 65 years and older, who lived in a catchment area and who, in the opinion of a physician not involved in the

See also:

Print

Editors' Notes . . . . . . . . . . . . . . . . . . . . . . 799

Editorial comment. . . . . . . . . . . . . . . . . . . . . 840

Summary for Patients. . . . . . . . . . . . . . . . . I-56

Web-Only

Conversion of figure and tables into slides tems (7-14).

Previous research in the United States has been limited

Improving Patient Care is a special section within Annals supported in part by the U.S. Department of Health and Human Services (HHS) Agency for Healthcare Research and Quality (AHRQ). The opinions expressed in this article are those of the authors and do not represent the position or endorsement of AHRQ or HHS. 
Hospital at Home 1 Improving Patient Care

study, required admission to an acute care hospital for 1 of 4 target illnesses: community-acquired pneumonia, exacerbation of chronic heart failure, exacerbation of chronic obstructive pulmonary disease, or cellulitis. Patients were required to meet validated criteria of medical eligibility for hospital-at-home care (16), which were designed to identify patients who would be medically suitable for this type of treatment. The most common reasons for medical ineligibility were uncorrectable hypoxemia (oxygen saturation $<90 \%$ ), suspected myocardial ischemia, and presence of an acute illness, other than the target illness, for which the patient was required to be hospitalized.

\section{Study Design}

This study was a prospective quasi-experiment conducted in 2 consecutive 11-month phases. During the acute care hospital observation phase (1 November 1990 to 30 September 2001), eligible patients were identified and followed through usual hospital care. Study coordinators verified the patient's eligibility for hospital-at-home care using a standard protocol at the time of enrollment. During this observation phase of the study, most patients were identified the morning after admission. These patients made up the acute hospital observation comparison group. During the intervention phase (1 November 2001 to 30 September 2002), eligible patients were identified at the time of admission and were offered the option of receiving their care in hospital at home rather than in the acute care hospital. Patients who chose hospital-at-home treatment were never admitted to the acute care hospital but received treatment, after initial evaluation (usually in the emergency department), in their home. The intervention group comprised all patients eligible for hospital-at-home care, irrespective of where they were treated.

\section{Approval}

The institutional review boards from each study site, the coordinating center, and officials at the Center for Health Plans and Providers at the Centers for Medicare \& Medicaid Services (CMS) gave their approval for the study. All participants provided informed written consent.

\section{Study Sites}

The study was conducted in 3 Medicare managed care (Medicare + Choice) plans at 2 sites and at a Veterans Administration medical center. Univera Health and Independent Health, in Buffalo, New York, are Medicare + Choice plans that operate in an independent practice association model. These 2 plans collaborated to provide hospital-at-home care and made up 1 study site (site 1). The Fallon Health Care System (site 2), in Worcester, Massachusetts, operates a not-for-profit Medicare + Choice plan, and the Fallon Clinic, a for-profit multispecialty physician group, provides care on a capitated basis to Medicare + Choice beneficiaries. The Portland, Oregon, Veterans Administration Medical Center (site 3) is a quaternary care and teaching facility.

\section{Context}

Hospital care for older people often means iatrogenic complications and a decline in function. Home hospital care might reduce these adverse outcomes.

\section{Content}

Patients were 65 years of age or older and required hospital care for pneumonia, heart failure, chronic obstructive pulmonary disease, or cellulitis. In phase I, they were hospitalized. In phase II, they could choose home hospital care (continuous nursing care followed by at least daily visits from a nurse and a physician). Sixty percent of patients chose home hospital care. Patients who received this type of care had shorter stays; fewer procedures, consultations, and indwelling devices; less delirium; greater satisfaction; and similar functional outcomes.

\section{Cautions}

The study was nonrandomized, and data were missing.

\section{Conclusion}

Home hospital care may be a good alternative for selected patients.

-The Editors

\section{Assessments}

Age, gender, and primary diagnosis were obtained for all eligible patients. Informed written consent was required for all additional data collection: medical record review, cost data review, and interviews. Staff trained at the coordinating center used standard procedures outlined in a detailed training manual to conduct all interviews, assessments, and medical record reviews. At baseline, interrater reliability was verified among the staff. Quality checks of medical record reviews were done midway through the study. Interrater reliability for ratings on the components of the daily patient interview was confirmed in 13 paired observations $(\kappa=0.91)$. Interrater reliability among study sites was similar.

\section{Medical Record Reviews}

Medical records were abstracted by using a standardized instrument that captured illness acuity, health status, medication use, results of laboratory tests, treatments, the hospital course and complications, health outcomes, and whether treatment standards were met. Illness acuity was determined by using the Acute Physiology and Chronic Health Evaluation II (APACHE II) score (17). Health status was measured by using clinical indicators appropriate to the diagnoses, a checklist of chronic medical conditions, and the Charlson comorbidity index (18). Medication use was defined as the number of prescribed medications taken on a daily basis at the time of admission. Diagnostic and therapeutic interventions were categorized as potentially "difficult" or "not difficult" to do in the home. The patient's clinical course was characterized according to

6 December $2005 \mid$ Annals of Internal Medicine $\mid$ Volume 143 • Number $11 \mid 799$ 
whether emergency situations (those that required physician evaluation within 30 minutes, such as the development of acute shortness of breath) or critical complications (death, transfer to intensive care setting, intubation, or myocardial infarction) occurred. Clinical care was examined with regard to completion of illness-specific standards of care (19-21).

Eligible patients who consented to participate completed a baseline interview that included demographic information, self-reported health status, assessment of sleep, Katz activities (22), Lawton instrumental activities of daily living (23), continence, mobility, the Geriatric Depression Scale (24), Jaeger vision test, the Mini-Mental State Examination (MMSE) (25), the Digit Span Test (26), and evaluation by the Confusion Assessment Method (CAM) (27). Subsequently, patients were evaluated daily until discharge by using a structured interview consisting of the MMSE, Digit Span Test, and CAM rating. A family member, caregiver, or person who knew the patient well was interviewed at the time of admission to complete the modified Blessed Dementia Rating Scale (28). At 2 weeks after admission, patients and family members were interviewed by telephone to obtain the patient's current functional status and to assess his or her satisfaction with care.

\section{Intervention: The Hospital-at-Home Model of Care}

The hospital-at-home model of care has been described previously (15). Briefly, a patient requiring admission to the acute care hospital for a target illness was identified in an emergency department or ambulatory site and his or her eligibility status was determined. Nonstudy medical personnel, usually emergency department physicians, made the decision to hospitalize the patient. All patients who were offered but who declined hospital-at-home care were admitted to the acute care hospital.

After informed consent was obtained, the patient was transported home by an ambulance. Patients were evaluated by the hospital-at-home physician either in the emergency department or shortly after arriving at home. Patients who required oxygen therapy were sent home with a portable oxygen apparatus pending delivery of home oxygen therapy. The hospital-at-home nurse met the ambulance at the patient's home. The patient had subsequent direct one-on-one nursing supervision for an initial period of at least 8 hours at site 3 and for a period of 24 hours at sites 1 and 2 .

When direct nursing supervision was no longer required, the patient had intermittent nursing visits at least daily. The hospital-at-home physician made at least daily home visits and was available 24 hours a day for urgent or emergent visits. Nursing and other care components, such as durable medical equipment, oxygen therapy, skilled therapies, and pharmacy support, were provided by a partner Medicare-certified home health agency, and for some services, such as home radiology, support was provided by independent contractors. A Lifeline device (Lifeline Sys- tems Inc., Framingham, Massachusetts) was placed in the home of any patient who did not have a family member present. Diagnostic studies, such as electrocardiography and radiography; intravenous fluids, intravenous antimicrobial agents, and other medications; and oxygen and other respiratory therapies were provided at home. Illnessspecific hospital-at-home care maps, clinical outcome evaluations, and specific discharge criteria were developed and provided a pathway for care. The patient was followed by the same hospital-at-home physician until his or her condition was stable enough for discharge, at which time care reverted to the primary care physician.

\section{Outcomes}

Process-of-care measures included time to first physician visit in the home, arrival of the nurse, and delivery of oxygen or medications. Additional process outcomes included hours of one-on-one nursing supervision, mean number of physician and intermittent nursing visits, treatments received, use of consultative services, and whether illness-specific standards of care were met.

Clinical outcomes included emergency situations and critical complications and various complications, including incident delirium. Incident delirium was defined as the acute onset and fluctuating course of symptoms of delirium, inattention, and either disorganized thinking or an altered level of consciousness according to the CAM criteria (27). Subsyndromal delirium was defined as the acute onset and fluctuating course of symptoms of delirium and either inattention or disorganized thinking or an altered level of consciousness (29). Each CAM feature was rated by study nurses on the basis of observations made during daily interviews. Incident delirium was defined as present or absent. Adjudication of delirium ratings was done by 2 independent reviewers who were unaware of the participant's study group. Satisfaction with care was measured by using a modified Picker Hospital Survey (30). A summary score was derived based on satisfaction with admission and discharge processes; relations with physician, nurses, and staff; and safety, comfort, and pain control (patients only). Possible scores ranged from 0 to 9 and 0 to 8 for patients and family members, respectively. Functional status was measured by using a summary score for activities of daily living (range, 0 to 5 ) and for instrumental activities of daily living (range, 0 to 7 ).

Costs of care were calculated. In the Medicare + Choice settings, we obtained data from the managed care organizations on the total amounts paid by the plan and by the patients during the index hospitalization in either the acute care hospital or the hospital-at-home setting. For the Veterans Administration medical center, we obtained an estimate of the costs of each patient's care based on a stepdown approach that allocates overhead charges in addition to the costs of care directly associated with the patient. We chose to use these amounts to focus on the cost for which 
Figure. Patient flow and data availability by study phase and site.

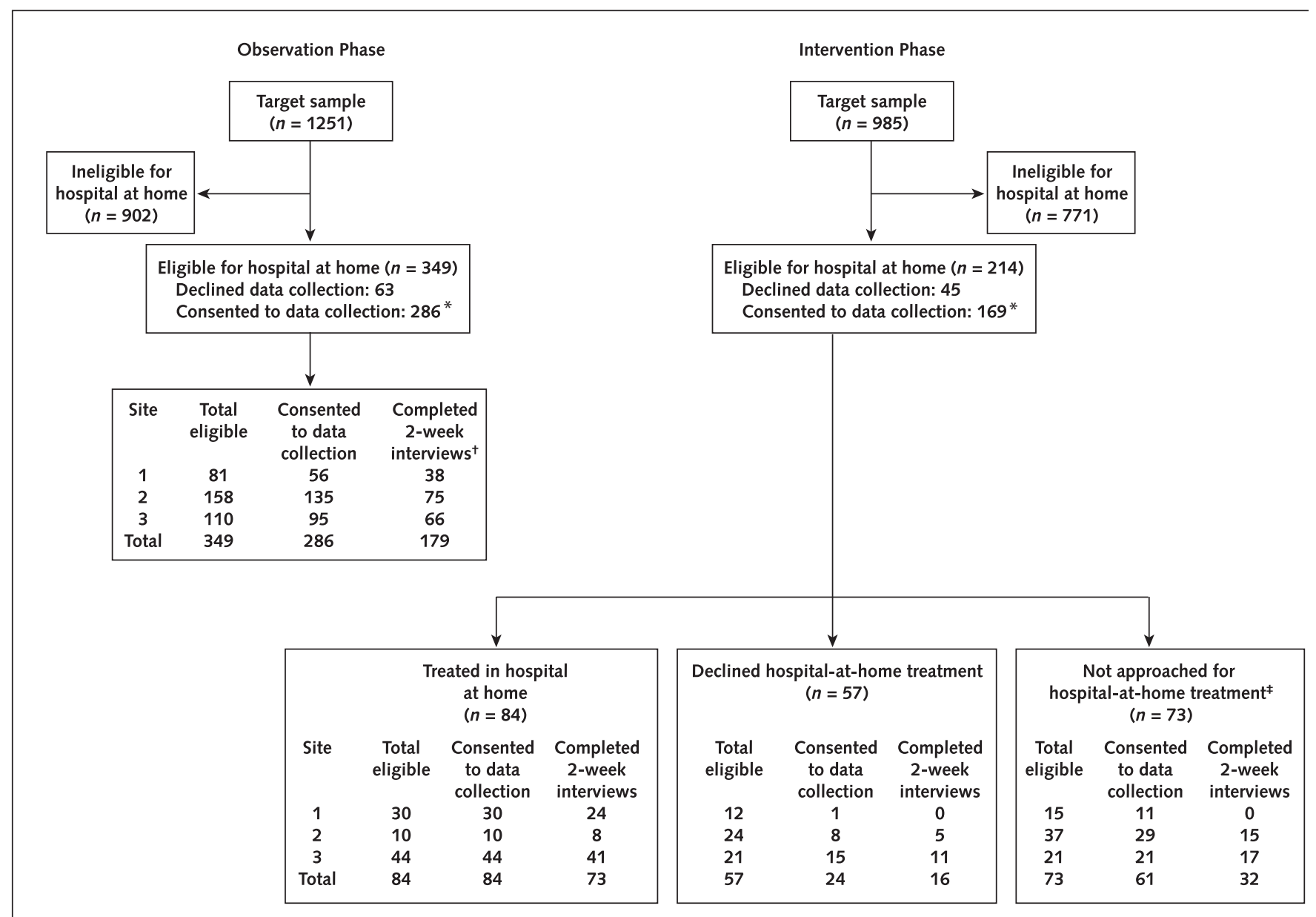

* Consented at least to medical record review and review of cost data. † Consented to review of medical records and cost data and completed baseline interview and 2-week follow-up interview. $¥$ Not approached for hospital-at-home treatment because hospital at home was not open for admissions between 10:00 p.m. and 6:00 a.m.

each payer in the current financing system was responsible. For hospital-at-home care, the costs of staff were included.

\section{Safety Monitoring}

Each of the study sites convened a patient safety committee that reviewed hospital-at-home cases. A Coordinating Center Data Safety Monitoring Board met 3 times during the intervention phase.

\section{Statistical Analysis}

We conducted exploratory analyses to examine all baseline demographic and health status characteristics at each study site. A priori, we conducted a pooled analysis of participants from the 3 study sites. In addition, we calculated the results from individual study sites.

All analyses were done on an intention-to-treat basis, in which participants from the observation group who were treated in the acute care hospital were compared with participants in the intervention group, regardless of whether they were treated in hospital at home or in the acute care hospital. A complete-case analysis was con- ducted and assumed that data were missing completely at random. The respective proportion of participants in the observation and intervention groups across study sites who consented to review of costs and medical records (82\% vs. $78 \%$ ), who consented to the baseline interview (66\% vs. $67 \%$ ), and who completed a 2-week follow-up telephone interview ( $51 \%$ vs. $57 \%$ ) were similar. Thus, this assumption seemed reasonable, although for end points with substantial amounts of missing data, such as incident delirium, satisfaction with care, and function, bias cannot be ruled out and results must be interpreted cautiously.

We evaluated the effect of the intervention on clinical complications by using logistic regression for dichotomous variables with sufficient numbers of events; otherwise, the Fisher exact test is reported. We dichotomized a variable for site comparing site 2 versus sites 1 and 3 . This was justified because relatively few participants in the intervention phase received actual hospital-at-home care at site 2 . The unadjusted model examines the effect of the interven- 
tion. We then controlled for study phase and the interaction between site and study phase. The interaction term was never statistically significant and thereafter was not included as a covariate. In the adjusted model, the following covariates were added on the basis of differences in participant characteristics and factors that we postulated could influence clinical outcomes: age, gender, APACHE II score, and study site.

The analysis of incident delirium was limited to participants who did not have prevalent delirium at the time of admission and who had 2 or more CAM assessments: 173 patients in the observation group and 127 in the intervention group. There were no differences in delirium risk factor profiles between patients with 2 or more CAM assessments and those with only 1 CAM assessment. A proportional hazards model, as well as Kaplan-Meier analysis and the log-rank test, were used to compare the cumulative incidence of delirium, which was defined as the probability that delirium would develop by a specified time. Assumptions of the proportional hazards model were tested and were met. A similar approach was taken for covariate selection as for other outcomes, except for the inclusion of additional specific delirium risk factors of visual impairment, cognitive impairment, and dehydration.

Satisfaction data were explored. Differences in the median number of domains in which patients or caregivers were satisfied were examined by study phase by using Wilcoxon rank-sum tests. To test for the effect of covariates, scores were dichotomized as at or above versus below the median and were controlled for in the logistic regression analysis. Covariates for patient satisfaction were Geriatric Depression Scale score, more than 1 limitation in activities or instrumental activities of daily living, primary diagnosis, a caregiver who was limited in at least 1 activity or instrumental activity of daily living, or a low MMSE score; covariates for family member satisfaction were patient living at the poverty level, primary diagnosis, having a child as a caregiver, or number of prescription medications being taken.
The change in scores for activities of daily living and instrumental activities of daily living was computed by taking the difference in scores between the baseline interview that assessed functional status 2 weeks before admission and the interview done 2 weeks after admission. Linear regression was used to control for covariates.

To compare costs, the mean amount paid by treatment method was combined across all 3 sites. We adjusted for inflation to September 2002 levels by using separate monthly consumer price index indicators for hospital and professional costs, including the costs of hospital-at-home staff. Because of the non-normal distribution, the statistical significance of differences in amount paid was tested by using nonparametric bootstrapping (1000 repetitions) with bias-corrected 95\% CIs. Target accrual for the study was pragmatic.

All analyses were conducted using SAS, version 8.2 (SAS Institute, Inc., Cary, North Carolina), or Stata, version 8.0 (Stata Corp., College Station, Texas).

\section{Role of the Funding Sources}

The funding sources had no role in the design, conduct, or reporting of the study or in the decision to submit the manuscript for publication.

\section{RESULTS}

The Figure shows patient groups by study phase and by site. During the observation phase, there were 1251 patients in the target sample. Three hundred forty-nine (28\%) were medically eligible for the study, of whom 286 $(82 \%)$ consented to data collection; these made up the acute care hospital observation group. During the intervention phase of the study, there were 985 patients in the target sample, of whom 214 (22\%) were medically eligible for the study. Of these patients, 141 were approached about receiving their care in hospital at home. Eighty-four received their care in this setting (overall, $60 \%$ of those approached $-71 \%$ at site $1,29 \%$ at site 2 , and $68 \%$ at site 3), 57 patients declined hospital-at-home care, and 73 pa-

Table 1. Treatment Status in Intervention Phase and Data Availability by Study Phase and Site

\begin{tabular}{|c|c|c|c|c|c|c|c|c|c|c|c|}
\hline \multirow[t]{2}{*}{ Variable } & \multicolumn{3}{|c|}{ Observation Phase } & \multicolumn{8}{|c|}{ Intervention Phase } \\
\hline & $\begin{array}{l}\text { Total } \\
\text { Eligible, } \\
n\end{array}$ & $\begin{array}{l}\text { Consented to } \\
\text { Data Collection, } \\
n(\%)^{*}\end{array}$ & $\begin{array}{l}\text { Completed } \\
\text { 2-Week } \\
\text { Interviews, } \\
n(\%) \dagger\end{array}$ & $\begin{array}{l}\text { Total } \\
\text { Eligible, } \\
n\end{array}$ & $\begin{array}{l}\text { Consented } \\
\text { to Data } \\
\text { Collection, } \\
n(\%)^{*}\end{array}$ & $\begin{array}{l}\text { Completed } \\
\text { 2-Week } \\
\text { Interviews, } \\
n(\%)+\end{array}$ & $\begin{array}{l}\text { Treated in } \\
\text { Hospital } \\
\text { at Home, } \\
n\end{array}$ & $\begin{array}{l}\text { Declined } \\
\text { Hospital- } \\
\text { at-Home } \\
\text { Treatment, } \\
n\end{array}$ & $\begin{array}{l}\text { Not } \\
\text { Approached } \\
\text { for Hospital- } \\
\text { at-Home } \\
\text { Treatment, nf }\end{array}$ & $\begin{array}{l}\text { Offered } \\
\text { Hospital- } \\
\text { at-Home } \\
\text { Treatment, } \\
\% \S\end{array}$ & $\begin{array}{l}\text { Accepted } \\
\text { Hospital- } \\
\text { at-Home } \\
\text { Treatment, } \\
\% \|\end{array}$ \\
\hline Site 1 & 81 & $56(69)$ & $38(47)$ & 57 & $42(74)$ & $24(42)$ & 30 & 12 & 15 & 74 & 71 \\
\hline Site 2 & 158 & $135(85)$ & $75(48)$ & 71 & $47(66)$ & 28 (39) & 10 & 24 & 37 & 48 & 29 \\
\hline Site 3 & 110 & $95(86)$ & $66(60)$ & 86 & $80(93)$ & $69(80)$ & 44 & 21 & 21 & 77 & 68 \\
\hline $\begin{array}{r}\text { Total by } \\
\text { phase }\end{array}$ & 349 & $286(82)$ & $179(51)$ & 214 & $169(79)$ & $121(57)$ & 84 & 57 & 73 & 66 & 60 \\
\hline
\end{tabular}

* Consented to at least medical record review and review of cost data.

† Consented to review of medical records and cost data; completed baseline interview; and completed 2-week follow-up interview.

¥ Not approached for hospital-at-home treatment because the patient required admission at times when hospital at home was not open for admissions (between 10:00 p.m. and 6:00 a.m.)

$\S$ Defined as the number of participants treated in hospital at home + the number who declined hospital-at-home treatment/total number of intervention participants.

|| Defined as the number of participants treated in hospital at home/number of participants offered hospital-at-home treatment. 
Hospital at Home

Table 2. Baseline Characteristics of Study Participants*

\begin{tabular}{|c|c|c|c|c|c|c|c|c|c|}
\hline Variable & $\begin{array}{l}\text { Observation } \\
\text { Group } \\
(n=286)\end{array}$ & $\begin{array}{l}\text { Intervention } \\
\text { Group } \\
(n=169)\end{array}$ & $\begin{array}{l}P \\
\text { Value }\end{array}$ & $\begin{array}{l}\text { Observation } \\
\text { Group } \\
(n=56)\end{array}$ & $\begin{array}{l}\text { Intervention } \\
\text { Group } \\
(n=42)\end{array}$ & $\begin{array}{l}\text { Observation } \\
\text { Group } \\
(n=135)\end{array}$ & $\begin{array}{l}\text { Intervention } \\
\text { Group } \\
(n=47)\end{array}$ & $\begin{array}{l}\text { Observation } \\
\text { Group } \\
(n=95)\end{array}$ & $\begin{array}{l}\text { Intervention } \\
\text { Group } \\
(n=80)\end{array}$ \\
\hline Mean age (SD), $y$ & $77.3(6.6)$ & $77.2(7.0)$ & 0.812 & $76.2(7.1)$ & $76.2(7.0)$ & $78.5(6.7)$ & $80.3(6.4)$ & $76.4(5.8)$ & $75.8(6.8)$ \\
\hline Gender (male), \% (n) & $66(111)$ & $58(165)$ & 0.092 & 41 & 36 & 40 & 40 & 93 & 96 \\
\hline Race (white), \% (n) & $90(257)$ & 86 (145) & 0.192 & 80 & 79 & 96 & 87 & 86 & 89 \\
\hline $\begin{array}{l}\text { Education (less than or } \\
\text { equal to high school), } \\
\%(n) \dagger\end{array}$ & $34(78)$ & $36(50)$ & 0.651 & 33 & 41 & 40 & 39 & 25 & 33 \\
\hline Live alone, \% (n)† & $43(122)$ & $33(55)$ & 0.022 & 45 & 43 & 47 & 38 & 38 & 25 \\
\hline $\begin{array}{l}\text { Any impairment in ADLs, } \\
\%(n) \dagger\end{array}$ & $44(100)$ & $45(63)$ & 0.821 & 37 & 57 & 38 & 31 & 56 & 46 \\
\hline $\begin{array}{l}\text { Any impairment in IADLs, } \\
\%(n)+\end{array}$ & 65 (149) & $64(90)$ & 0.852 & 57 & 70 & 66 & 63 & 68 & 62 \\
\hline $\begin{array}{l}\text { Mean of chronic medical } \\
\text { conditions (SD), } n\end{array}$ & $5.8(2.7)$ & $5.9(2.5)$ & 0.608 & $5.2(3.1)$ & $5.9(3.0)$ & $5.3(2.3)$ & $5.4(2.4)$ & $6.9(2.7)$ & $6.3(2.2)$ \\
\hline $\begin{array}{l}\text { Mean Charlson comorbidity } \\
\text { index (SD)§ }\end{array}$ & $3.1(2.0)$ & $3.0(1.8)$ & 0.849 & $2.7(2.3)$ & $2.7(1.6)$ & $2.6(1.6)$ & $2.5(1.8)$ & $3.9(2.1)$ & $3.5(1.8)$ \\
\hline $\begin{array}{l}\text { Mean medications used as } \\
\text { outpatient (SD), } n\end{array}$ & 6.8 (3.9) & $8.1(4.5)$ & 0.002 & $6.5(4.3)$ & $6.4(3.7)$ & $6.2(3.2)$ & $5.8(3.0)$ & 7.9 (4.4)ף & $10.4(4.6)$ \\
\hline $\begin{array}{l}\text { Mean APACHE II score } \\
\text { (SD)\| }\end{array}$ & $12.6(2.9)$ & $11.6(3.4)$ & 0.006 & $12.8(4.3)$ & $11.4(3.7)$ & $12.4(3.7)$ & 11.9 (3.6) & 12.8 (3.9)ף & $11.5(3.1)$ \\
\hline \multicolumn{10}{|l|}{$\begin{array}{l}\text { Primary admission } \\
\text { diagnosis, \% (n) }\end{array}$} \\
\hline Pneumonia & $31(89)$ & $32(54)$ & 0.853 & $43 \pi$ & 21 & 299 & 47 & 27 & 28 \\
\hline COPD & $32(92)$ & $28(48)$ & 0.400 & $16 ף$ & 33 & 38 & 30 & 34 & 25 \\
\hline Cellulitis & $12(34)$ & $18(30)$ & 0.082 & 16 & 19 & 13 & 9 & 79 & 23 \\
\hline
\end{tabular}

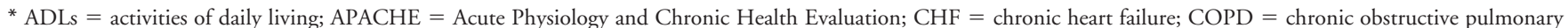
disease; DNR = do not resuscitate; IADLs = instrumental activities of daily living; MMSE = Mini-Mental State Evaluation.

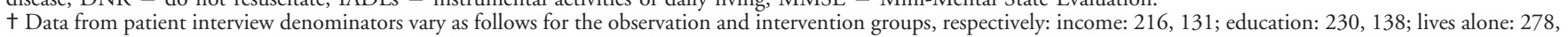
167; ADLs: 230, 141; IADLs: 230, 141; self-reported health: 229, 140.

¥ Higher score indicates higher level of cognitive function.

$\S$ Higher score indicates increasing level of comorbid conditions.

$\|$ Higher score indicates increasing level of illness acuity.

I $P \leq 0.050$ comparing the observation phase with the intervention phase at the site.

tients were not approached to enroll in hospital-at-home during the intervention phase of the study because hospital at home was not open for admissions between 10:00 p.m. and 6:00 a.m. Treatment status in the intervention phase and data availability by study phase and site are described in Table 1. The consent and complete case rates probably reflect the relatively low incentive to participate in a study with a relatively high interview burden for patients in the observation group as a whole and for patients in the intervention group who were treated in the acute care hospital. Other operative factors may have included a more amenable research sample at the Veterans Administration medical center (site 3) and a higher proportion of African-American patients at site 1 who were less willing to participate in the research. Neither death nor active withdrawal from the study contributed to these rates. In addition, an analysis of characteristics of participants who completed all data collection through the 2-week follow-up interviews showed that they did not differ substantially from the characteris- tics of participants who declined any type of data collection at the site level or in the aggregate in each study phase.

Characteristics of the study samples are shown in Table 2. Overall, patients were elderly, white, and had a high burden of functional impairments and comorbid illnesses. Patients in the observation group and those in the intervention group were similar, but patients in the intervention phase were more likely to live in poverty, live alone, take more prescription medication on a daily basis as an outpatient, and have a lower illness acuity score. Aggregate differences among participants at sites 1, 2, and 3, respectively, were limited to age (76.2 years vs. 78.9 years vs. 76.1 years; $P<0.001$ ), proportion of male participants (39\% vs. $40 \%$ vs. $94 \% ; P<0.001)$, proportion of white participants ( $80 \%$ vs. $94 \%$ vs. $87 \% ; P=0.002)$, number of comorbid conditions $(5.5$ vs. 5.3 vs. $6.6 ; P<$ $0.001)$, and number of prescription medications used (6.4 vs. 6.1 vs. 9.0; $P<0.001)$. Within-site differences between the observation and intervention phases are described in Table 2.

Clinical care measures, including measures of hospital- 
Improving Patient CARE

Table 3. Comparison of Clinical Care Measures in Observation and Intervention Groups*

\begin{tabular}{|c|c|c|c|c|c|c|c|c|c|}
\hline \multirow[t]{2}{*}{ Variable } & \multicolumn{3}{|c|}{ All Sites } & \multicolumn{2}{|r|}{ Site 1} & \multicolumn{2}{|r|}{ Site 2} & \multicolumn{2}{|r|}{ Site 3} \\
\hline & $\begin{array}{l}\text { Observation } \\
\text { Group } \\
(n=286)\end{array}$ & $\begin{array}{l}\text { Intervention } \\
\text { Group } \\
(n=169)\end{array}$ & $P$ Valuet & $\begin{array}{l}\text { Observation } \\
\text { Group } \\
(n=56)\end{array}$ & $\begin{array}{l}\text { Intervention } \\
\text { Group } \\
(n=42)\end{array}$ & $\begin{array}{l}\text { Observation } \\
\text { Group } \\
(n=135)\end{array}$ & $\begin{array}{l}\text { Intervention } \\
\text { Group } \\
(n=147)\end{array}$ & $\begin{array}{l}\text { Observation } \\
\text { Group } \\
(n=95)\end{array}$ & $\begin{array}{l}\text { Intervention } \\
\text { Group } \\
(n=80)\end{array}$ \\
\hline $\begin{array}{l}\text { Mean time between arrival } \\
\text { home and } \\
\text { hospital-at-home } \\
\text { physician evaluation } \\
\text { (range) [SD], } \\
h \neq \S\end{array}$ & NA & $1.8(0-4.5)[1.0]$ & NA & NA & $1.9(0-4.2)[1.0]$ & NA & $2.1(1.3-3.5)[0.7]$ & NA & $1.6(0-4.5)[1.1]$ \\
\hline $\begin{array}{l}\text { Mean time to arrival of } \\
\text { nurse at home, (range) } \\
\text { [SD], h‡ }\end{array}$ & NA & $0.3(0-3.3)[0.6]$ & NA & NA & $0.3(0-0.3)[0.7]$ & NA & $0.3(0-2.0)[0.7]$ & NA & $0.3(0-1.8)[0.4]$ \\
\hline $\begin{array}{l}\text { Mean time to arrival of } \\
\text { oxygen at home } \\
\text { (range) [SD], } h \neq\end{array}$ & NA & $2.2(0-12)[3.6]$ & NA & NA & $0.7(0-2.3)[0.8]$ & NA & $0.6(0-1.4)[0.7]$ & NA & $3.3(0-12.0)[4.4]$ \\
\hline $\begin{array}{l}\text { Mean time to arrival of } \\
\text { initial set of medications } \\
\text { at home (range) [SD], } \\
h \neq\end{array}$ & NA & $1.1(0-4.8)[1.2]$ & NA & NA & $0.8(0-3.7)[1.1]$ & NA & $0.6(0-3.0)[1.1]$ & NA & $1.3(0-4.8)[1.3]$ \\
\hline $\begin{array}{l}\text { Mean continuous nursing } \\
\text { (range) }[\mathrm{SD}], h \neq \|\end{array}$ & NA & $16.9(0-71)[14.6]$ & NA & NA & $17.7(0-71.0)[20.1]$ & NA & $29.1(18.0-50.0)[11.0]$ & NA & $13.5(3.0-43.0)$ [8.1] \\
\hline $\begin{array}{l}\text { Mean physician visits per } \\
\text { day (range) [SD], } n \neq\end{array}$ & NA & $1.5(0.8-2.0)[0.3]$ & NA & NA & $1.4(0.8-2.0)[0.4]$ & NA & $1.1(1.0-1.3)[0.3]$ & NA & $1.6(1.2-2.0)[0.3]$ \\
\hline $\begin{array}{l}\text { Mean intermittent nursing } \\
\text { visits per day (range) } \\
\text { [SD], } n \neq\end{array}$ & NA & $1.4(0-5.3)[0.9]$ & NA & NA & $1.6(0-5.3)[1.3]$ & NA & $1.2(0-3.0)[0.9]$ & NA & $1.3(0-2.5)[0.6]$ \\
\hline $\begin{array}{l}\text { Mean time spent in } \\
\text { emergency department } \\
\text { (range) [SD], } h\end{array}$ & $5.5(1.0-21.3)[3.2]$ & $6.4(1.8-11.6)$ [1.9] & 0.001 & NA & $6.4(2.5-11.0)[2.0]$ & NA & $6.5(5.2-7.8)[1.1]$ & NA & $6.4(1.8-10.5)$ [1.9] \\
\hline $\begin{array}{l}\text { Admitted from emergency } \\
\text { department, \% (n) }\end{array}$ & $91(256)$ & $91(148)$ & 0.995 & 85 & 90 & 96 & 89 & 87 & 92 \\
\hline $\begin{array}{l}\text { Mean length of stay (SD), } \\
d\end{array}$ & $4.9(9.9)$ & $3.2(2.5)$ & 0.004 & $8.0(20.8)$ & $3.6(2.7)$ & $4.1(4.3)$ & $3.6(2.6)$ & $4.4(3.8)^{* *}$ & $2.7(2.1)$ \\
\hline $\begin{array}{l}\text { Median length of stay } \\
\quad \text { (interquartile range), } d \text { ๆ }\end{array}$ & $3.0(2-5)$ & $2.0(2-4)$ & $<0.0001$ & $4(3-7)^{* *}$ & $3(2-4)$ & $3(2-5)$ & $3(2-5)$ & $3(2-5)^{* *}$ & $2(2-3)$ \\
\hline Oxygen, \% (n) & $76(217)$ & $73(123)$ & 0.463 & 82 & 76 & 79 & 77 & 67 & 69 \\
\hline $\begin{array}{l}\text { Intravenous antibiotics, } \\
\%(n)\end{array}$ & $76(217)$ & 76 (128) & 0.964 & 89ף & 74 & 79 & 85 & 64 & 71 \\
\hline $\begin{array}{l}\text { Nebulized bronchodilators, } \\
\quad \%(n)\end{array}$ & $49(140)$ & $49(83)$ & 0.974 & 48 & 50 & 61 & 58 & 33 & 44 \\
\hline $\begin{array}{l}\text { Intravenous fluids, } \\
\%(n)++\end{array}$ & $27(76)$ & $18(31)$ & 0.046 & $32 * *$ & 5 & $23^{* *}$ & 38 & $28^{* *}$ & 14 \\
\hline Foley catheter, \% ( $n$ ) & $23(67)$ & $14(23)$ & 0.011 & 16 & 12 & 30 & 23 & 19 & 9 \\
\hline $\begin{array}{l}\text { Any difficult procedures, } \\
\%(n) \neq \neq\end{array}$ & $65(185)$ & $32(54)$ & $<0.001$ & $54^{* *}$ & 7 & 67 & 57 & $68^{* *}$ & 30 \\
\hline $\begin{array}{l}\text { Mean difficult procedures } \\
\text { (SD), } n\end{array}$ & $1.5(1.8)$ & $0.7(1.2)$ & $<0.001$ & $1.0(1.5)^{* *}$ & $0.1(0.5)$ & $1.5(1.8)$ & $1.3(1.6)$ & $2.0(2.0)^{* *}$ & $0.6(1.1)$ \\
\hline Mean consultation (SD), $n$ & $1.5(1.5)$ & $0.8(1.3)$ & $<0.001$ & $1.7(1.6)^{* *}$ & $0.3(0.6)$ & $1.3(1.3)$ & $1.4(1.6)$ & $1.8(1.7)^{* *}$ & $0.7(1.2)$ \\
\hline $\begin{array}{l}\text { Any patient with } \geq 1 \\
\text { consultation, \% (n) }\end{array}$ & $70(201)$ & $36(60)$ & $<0.001$ & $70^{* *}$ & 19 & 69 & 58 & $73^{* *}$ & 31 \\
\hline
\end{tabular}

* NA $=$ not applicable.

† $P$ value comparing observation versus intervention groups combined across sites.

¥ Applies only to the 84 patients in the intervention group who received hospital-at-home treatment.

$\S$ Includes values of 0 for patients seen in the emergency department by a hospital-at-home physician.

$\|$ Includes values of 0 for patients who declined continuous nursing care.

I $P$ value by Wilcoxon rank-sum, for median length of stay.

** $P \leq 0.050$ comparing the observation phase with the intervention phase at the site.

†† Excluding patients with a primary diagnosis of chronic heart failure.

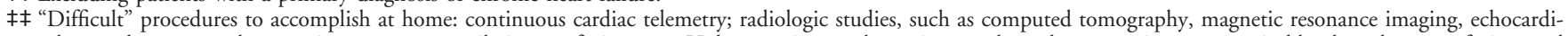

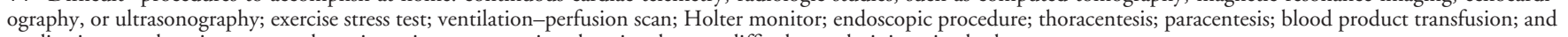
medications, such as intravenous heparin or intravenous nitroglycerin, that are difficult to administer in the home.

at-home feasibility, are shown in Table 3. Process outcomes for patients who received hospital-at-home care in the aggregate and at the site level show that this model was feasible: Nurses and physicians arrived promptly, and systems to deliver oxygen and medications functioned well and met standards established by the investigators. The mean and median lengths of stay for patients who received hospital-at-home care were substantially shorter than those for patients who were treated in the acute care hospital, with the shortest hospital-at-home length of stay at site 3 . Care processes usually associated with hospital-level care, such as oxygen therapy, intravenous antibiotics, and nebulized bronchodilators, were used at similar rates. However, patients treated in the hospital at home were less likely to receive intravenous fluids, have a urinary catheter, have a "difficult" procedure performed, or have a consultation of any sort. At the site level, these differences were seen at sites 1 and 3 but not at site 2, where few patients received actual hospital-at-home care. At site 2, there were no statistically significant differences between the observation and intervention groups, except for the increased use of intravenous fluids in patients in the intervention group. This may have been related to the increased proportion of patients in the intervention group with community-acquired pneumonia who were treated at site 2 . Illness-specific standards of care were met in similar proportions in both study groups at the aggregate and site levels (Table 4).

Complications experienced by patients in each of the 
study groups are described in Table 5. The rate of incident delirium, including subsyndromal delirium, was $9 \%$ in the intervention group and $24 \%$ in the observation group. This difference remained significant in survival analyses (adjusted hazard ratio, 0.26 [95\% CI, 0.12 to 0.57]). These results should be interpreted cautiously because data on delirium were not available for $42 \%$ of the sample. In addition, patients in the intervention group were less likely to have a sedative medication prescribed (adjusted odds ratio, 0.49 [CI, 0.30 to 0.81$]$ ). The small number of several outcomes precluded adjusted analyses. However, in the intervention group, there was a reduction in the use of chemical restraints, a trend toward reduction in the use of physical restraints, fewer critical complications, and a lower death rate. Again, at the site level, these differences were most apparent at sites 1 and 3. Two patients who initially received hospital-at-home care completed their treatment in the acute care hospital. One patient with chronic obstructive pulmonary disease had an episode of oxygen desaturation that did not respond initially to intensive bronchodilator treatment. Another patient with pneumonia insisted on using the bathroom alone, despite the presence of a nursing assistant. He fell and sustained a thoracic vertebral burst fracture, from which he recovered well.

Satisfaction of patients (median, 7 vs. 6 domains; $P<$ 0.001 ) and family members (median, 6 vs. 5 domains; $P<$ 0.001 ) was greater in the intervention group and remained statistically significant when controlled for covariates. In unadjusted and adjusted analyses, there were no differences in change in activities of daily living (0.04 vs. $0.09 ; P=$ 0.711 ) or in status of instrumental activities of daily living scores between the observation and intervention groups at 2 weeks $(-0.07$ vs. $0.14 ; P=0.280)$. Given that satisfaction and functional outcomes were missing for $47 \%$ of participants, these results should be interpreted with caution because of the potential for bias.

The mean amounts paid for the index hospitalization for patients in the observation group and those in the intervention group were $\$ 7480$ (SD, \$8112) and $\$ 5081$ (SD, \$4427), respectively. Use of a nonparametric bootstrapping (31) approach to test for differences showed a difference in the amount paid for the index hospitalization at all 3 study sites (mean, \$2398 [CI, \$1376 to \$3631]). The results from the bootstrapping approach did not differ from those of the parametric tests.

Eight weeks after admission, there were no differences in use of health services between the patients in the observation and intervention groups regarding mean number of emergency department visits ( 0.23 vs. $0.22 ; P=0.846)$, mean number of inpatient hospital readmissions $(0.28$ vs. $0.27 ; P=0.892)$, mean number of admissions to skilled nursing facilities $(0.15$ vs. $0.18 ; P=0.511)$, or mean number of home health visits (1.80 vs. $1.78 ; P=0.971)$.

Table 4. Comparison of Illness-Specific Standards of Care in the Observation and Intervention Groups*

\begin{tabular}{|c|c|c|c|c|c|c|c|c|}
\hline \multirow[t]{2}{*}{ Variable } & \multirow{2}{*}{$\begin{array}{l}\text { Observation } \\
\text { Group } \\
(n=286)\end{array}$} & \multirow{2}{*}{$\begin{array}{l}\text { Intervention } \\
\text { Group } \\
(n=169)\end{array}$} & \multicolumn{2}{|c|}{ Site 1} & \multicolumn{2}{|c|}{ Site 2} & \multicolumn{2}{|c|}{ Site 3} \\
\hline & & & $\begin{array}{l}\text { Observation } \\
\text { Group }\end{array}$ & $\begin{array}{l}\text { Intervention } \\
\text { Group }\end{array}$ & $\begin{array}{l}\text { Observation } \\
\text { Group }\end{array}$ & $\begin{array}{l}\text { Intervention } \\
\text { Group }\end{array}$ & $\begin{array}{l}\text { Observation } \\
\text { Group }\end{array}$ & $\begin{array}{l}\text { Intervention } \\
\text { Group }\end{array}$ \\
\hline $\begin{array}{l}\text { Community-acquired pneumonia } \\
(n=143), n\end{array}$ & 89 & 54 & 24 & 9 & 39 & 22 & 26 & 23 \\
\hline $\begin{array}{l}\text { Antibiotics within } 8 \text { hours of } \\
\text { admission, } \%(n)\end{array}$ & $96(85)$ & $93(50)$ & 100 & 89 & 97 & 91 & 89 & 96 \\
\hline $\begin{array}{l}\text { Blood cultures obtained before } \\
\text { administration of antibiotics, } \\
\%(n)\end{array}$ & $61(54)$ & $52(28)$ & 63 & 56 & 56 & 36 & 65 & 65 \\
\hline Chronic heart failure $(n=108), n$ & 71 & 37 & 14 & 11 & 27 & 7 & 30 & 19 \\
\hline $\begin{array}{l}\text { Documentation of left ventricular } \\
\text { function, \% (n) }\end{array}$ & $65(46)$ & $57(21)$ & 36 & 9 & 41 & 57 & 100 & 84 \\
\hline $\begin{array}{l}\text { Use or consideration of use of } \\
\text { angiotensin-converting enzyme } \\
\text { inhibitor or angiotensin-receptor } \\
\text { blocker, \% }(n)\end{array}$ & $68(48)$ & $78(29)$ & 50 & 73 & 48 & 43 & 93 & 95 \\
\hline $\begin{array}{l}\text { Use or consideration of use of } \\
\beta \text {-blocker, \% (n) }\end{array}$ & $66(47)$ & $78(29)$ & 43 & 73 & 52 & 71 & 90 & 84 \\
\hline $\operatorname{COPD}(n=140), n$ & 92 & 48 & 9 & 14 & 51 & 14 & 32 & 20 \\
\hline Use of corticosteroids, \% (n) & $88(81)$ & $85(41)$ & 89 & 93 & 90 & 79 & 84 & 85 \\
\hline $\begin{array}{l}\text { Use of nebulized bronchodilators, } \\
\%(n)\end{array}$ & $82(75)$ & $85(41)$ & 89 & 100 & 90 & 79 & 66 & 80 \\
\hline Use of antibiotics, \% (n) & $72(66)$ & $79(38)$ & 67 & 86 & 78 & 93 & 63 & 65 \\
\hline Cellulitis $(n=64), n$ & 34 & 30 & 9 & 8 & 18 & 4 & 7 & 18 \\
\hline $\begin{array}{l}\text { Antibiotics within } 8 \text { hours of } \\
\text { admission, \%(n) }\end{array}$ & $100(34)$ & $97(29)$ & 100 & 100 & 100 & 75 & 100 & 100 \\
\hline $\begin{array}{l}\text { Blood cultures obtained before } \\
\text { administration of antibiotics, } \\
\%(n)\end{array}$ & $50(17)$ & $47(14)$ & 67 & 38 & 44 & 50 & 43 & 50 \\
\hline
\end{tabular}

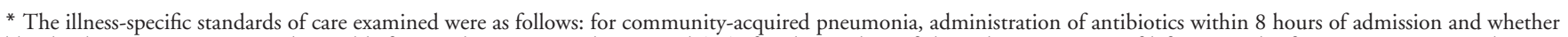

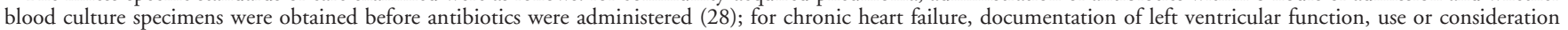

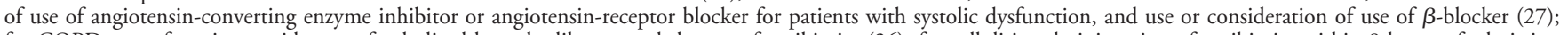

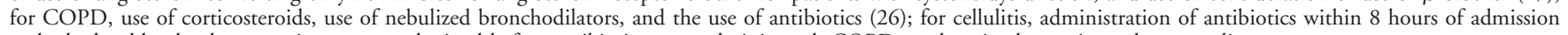
and whether blood culture specimens were obtained before antibiotics were administered. COPD $=$ chronic obstructive pulmonary disease. 
Improving Patient CARE

Table 5. Comparison of Clinical Complications Experienced by Participants in the Observation and Intervention Groups*

\begin{tabular}{|c|c|c|c|c|c|c|c|c|c|c|c|}
\hline \multirow[t]{2}{*}{ Variable } & \multicolumn{5}{|c|}{ All Sites } & \multicolumn{2}{|c|}{ Site 1} & \multicolumn{2}{|c|}{ Site 2} & \multicolumn{2}{|c|}{ Site 3} \\
\hline & $\begin{array}{l}\text { Observation } \\
\text { Group } \\
(n=286) \\
n(\%)\end{array}$ & $\begin{array}{l}\text { Intervention } \\
\text { Group } \\
(n=169) \\
n(\%)\end{array}$ & $\begin{array}{l}\text { Unadjusted } \\
\text { Odds Ratio } \\
(95 \% \mathrm{Cl}) \dagger\end{array}$ & $\begin{array}{l}\text { Adjusted } \\
\text { Odds Ratio } \\
(95 \% \mathrm{Cl}) \neq\end{array}$ & $\begin{array}{l}P \\
\text { Value§ }\end{array}$ & $\begin{array}{l}\text { Observation } \\
\text { Group } \\
(n=56) \\
\%\end{array}$ & $\begin{array}{l}\text { Intervention } \\
\text { Group } \\
(n=42) \\
\%\end{array}$ & $\begin{array}{l}\text { Observation } \\
\text { Group } \\
(n=135) \\
\%\end{array}$ & $\begin{array}{l}\text { Intervention } \\
\text { Group } \\
(n=47) \\
\%\end{array}$ & $\begin{array}{l}\text { Observation } \\
\text { Group } \\
(n=95) \\
\%\end{array}$ & $\begin{array}{l}\text { Intervention } \\
\text { Group } \\
(n=80) \\
\%\end{array}$ \\
\hline $\begin{array}{l}\text { Incident delirium (full } \\
\text { and subsyndromal)|| }\end{array}$ & $42(24)$ & $12(9)$ & $0.44(0.23-0.83)$ & $0.26(0.12-0.57)$ ๆ & & $28^{* *}$ & 8 & 18 & 18 & $18^{* *}$ & 5 \\
\hline Sedative medication use & $85(30)$ & $27(16)$ & $0.45(0.28-0.73)$ & $0.49(0.30-0.81)$ & & 21 & 12 & 31 & 23 & $32^{* *}$ & 14 \\
\hline Bowel complications & $47(16)$ & $15(9)$ & $0.50(0.27-0.92)$ & $0.57(0.30-1.07)$ & & 11 & 7 & 19 & 13 & $17^{* *}$ & 8 \\
\hline $\begin{array}{l}\text { Emergency situations } \\
\quad(\text { patients with } \geq 1)\end{array}$ & $31(11)$ & $10(6)$ & $0.52(0.25-1.08)$ & $0.62(0.29-1.34)$ & & $16^{* *}$ & 2 & 8 & 12 & 12 & 4 \\
\hline Chemical restraints & $20(7)$ & $3(2)$ & & & 0.014 & 4 & 0 & 11 & 6 & 4 & 0 \\
\hline Urinary complications & $18(6)$ & $5(3)$ & & & 0.128 & 4 & 5 & 11 & 4 & 1 & 1 \\
\hline Fall & $6(2)$ & $2(1)$ & & & 0.72 & 4 & 2 & 2 & 0 & 2 & 1 \\
\hline Physical restraints & $6(2)$ & $0(0)$ & & & 0.089 & 4 & 0 & 2 & 0 & 1 & 0 \\
\hline Nosocomial infection & $6(2)$ & $1(0.6)$ & & & 0.267 & 2 & 0 & 3 & 2 & 1 & 0 \\
\hline Death & $7(3)$ & $0(0)$ & & & 0.050 & 0 & 0 & 3 & 0 & 3 & 0 \\
\hline $\begin{array}{l}\text { Critical complications } \\
\quad(\text { patients with } \geq 1)\end{array}$ & $16(6)$ & $0(0)$ & & & $<0.001$ & 5 & 0 & 4 & 0 & $7^{* *}$ & 0 \\
\hline $\begin{array}{l}\text { Transfer from hospital at } \\
\text { home to acute } \\
\text { hospital }\end{array}$ & NA & $2(2)$ & & & & NA & 2 & NA & 2 & NA & 0 \\
\hline
\end{tabular}

* NA $=$ not applicable.

+ Odds ratio for intervention effect.

¥ Odds ratio for intervention effect adjusted for age, gender, Acute Physiology and Chronic Health Evaluation II score, and site.

$\S$ Fisher exact test probability reported.

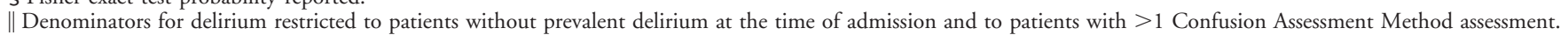

173 patients in the observation group and 127 patients in the intervention group, hazard ratio reported.

ๆ With additional specific delirium risk factors added as covariates: visual impairment, Mini-Mental State Examination $<24$, dehydration.

** $P \leq 0.050$ comparing the observation phase with the intervention phase at the site.

\section{Discussion}

To our knowledge, this is the first study of a hospitalat-home model in the United States that substitutes entirely for acute hospital care. The data suggest that this model is feasible and efficacious. In 2 of 3 sites studied, $69 \%$ of acutely ill older persons who were medically eligible and who were offered hospital-at-home care opted for this type of treatment. Patients received timely hospitallevel care at home that met quality standards. Compared with patients treated in the acute care hospital, those treated in the hospital at home had fewer important clinical complications, including use of sedative medications, use of chemical restraints, and incident delirium. Patient and family member satisfaction was higher in the hospitalat-home setting. In addition, the average amount paid for patients who received hospital-at-home care was lower than the amount paid for those who received care in the acute hospital setting.

In the literature, the definition of hospital at home is controversial (32). Most studies focus on outpatient intravenous infusion models and early hospital discharge schemes $(5,7)$. There have been fewer studies of substitutive hospital-at-home models in which patients avoid admission to an acute care hospital $(5,7-10,13,15)$. Compared with previous studies and models of substitutive hospital at home, our study is unique in several respects. First, our hospital-at-home model provided greater medical supervision than reported in previous studies. In most models, physician evaluation of patients in their homes is uncommon. For example, a recent systematic review of hospital-at-home care for patients with chronic obstructive pulmonary disease examined 7 studies, none of which pro- vided substantial physician involvement (33). In the current model, the patients had at least daily physician visits at home. Studies suggest that physician involvement may be crucial in ensuring patient acceptance of hospital-at-hometype care in the United States $(34,35)$. In addition, patients had initial one-on-one nursing care for an extended period (mean, 16.9 hours), followed by at least daily home visits by a nurse, and 24-hour physician coverage for urgent clinical situations. Overall, substantial medical supervision was appropriate because of the nature of the patients and their illnesses and could not have been provided in a timely manner with standard community-based home care services. Second, the current model provided an intensive level of medical services not offered in many studies of hospital-at-home care. For example, $78 \%$ of patients who were treated at hospital at home received oxygen therapy, whereas previous studies would have excluded patients who required oxygen (13) and another study would have excluded patients who required intravenous therapy or fulltime nursing care (9). Third, we reported on a wide range of outcomes, including clinical outcomes, satisfaction, function, and costs. Fourth, we demonstrated lower rates of complications, including incident delirium. An Australian study of patients who received hospital-at-home care reported a statistically significant decrease in delirium by reviewing medical records for evidence of "confusion" (13). In our study, the more rigorous assessment of the delirium outcome using the CAM probably better reflects the true rates of incident delirium and suggests that the care environment and process play a role in causing delirium (36). In addition, data for other clinical complications showed reduced odds ratios, although many were not statistically 
significant in adjusted analyses. This may reflect a true lack of differences in these outcomes or a lack of power to detect such differences. Fifth, we examined process measures, use of hospital procedures and consultations, and standards of care to understand how the process of hospital-at-home care differs from acute hospital care and to demonstrate that the former type of care is less procedurally oriented while still maintaining appropriate care standards. Finally, our hospital-at-home model was implemented simultaneously in several types of health systems.

The study has important limitations. Patients were not randomly assigned to treatment, and differences between study groups may be attributable to selection bias. However, we used a highly conservative intention-to-treat analysis, which may have attenuated reported effects of the hospital at home, and adjusted clinical outcomes for differences in patient characteristics. In addition, although approximately $80 \%$ of participants consented to review of medical records and cost data, smaller proportions consented to interviews and contributed data to the analysis of outcomes, such as incident delirium, satisfaction, and function. This may have introduced additional bias into the results, although patients with complete and missing data were similar according to known characteristics.

The study experience at site 2 is instructive. The recruitment experience at site 2 differed from that of the other study sites, with a lower rate of patients treated in hospital at home and a higher rate of patients not approached for this type of treatment. There are several possible explanations for this, including the development of disease management programs launched in that health system during the study, a local nursing shortage that precluded that site's ability to coordinate the one-on-one nursing care required to start a hospital-at-home admission, and other unmeasurable organizational factors. We do not believe that the staff model-type arrangements at site 2 were a factor and, in fact, submit that such an integrated health care delivery system may be ideal for implementation of hospital-at-home care.

Temporal trends may have affected the study. This is reflected in the decline in the target sample between the 2 study phases, which may have been attributable to a mild influenza season during the intervention phase (37), the implementation of case management interventions at some study sites that may have effectively reduced the need for hospital admissions, or both. Because the hospital-at-home model we studied was limited to patients with 4 diagnoses and was done at several Medicare + Choice plans and a Veterans Administration medical center, the results may not be generalizable to the treatment of patients with other illnesses, other samples of older persons, or other health systems.

Despite these limitations and the need for continued rigorous research in this area, our study shows that an innovative substitutive hospital-at-home model for selected older patients with common acute medical conditions is feasible and efficacious in selected health care systems. As the U.S. population ages and the burden of chronic disease and demand for acute hospital services increase, we believe that hospital at home, as a hospital-based unit, can play an important role in the health care system of the future.

From Johns Hopkins University School of Medicine, Johns Hopkins Bayview Medical Center, and The Johns Hopkins Bloomberg School of Public Health, Baltimore, Maryland; Portland Veterans Administration Medical Center and Oregon Health \& Science University, Portland, Oregon; State University of New York, Independent Health, and Univera Health, Buffalo, New York; Fallon Community Health Plan and Fallon Clinic, Worcester, Massachusetts; Beth Israel Deaconess Medical Center, Harvard Medical School, Boston, Massachusetts; and The John A. Hartford Foundation, New York, New York.

Note: Portions of this work have been presented at meetings of the American Geriatrics Society, May 2001, 2003, 2004; the Gerontological Society of America, November 2002, November 2003; and the American Academy of Home Care Physicians, May 2005.

Acknowledgments: The authors thank the following people without whom the study would not have been possible: Nurse Study Coordinators: Maggie Donius, Susan Saltzman, Christine Delano; Delirium Data Coordinators and other site personnel: Kristine Noonan, Lana McBride, Kathleen Chapman, Richard Harper, Wendy Wanlass, Carol Joseph, Nora Tobin, Jim Jackson, Joyce Holohan-Bell, Kay Schecter, Carol Baird, Sandie Taylor, Cleo Scribner, Kay Jenkins, Candace LaBlanc, Marcia Kirkpatrick, Diane Davies; Annette Hopkins for Confusion Assessment Method training and data review; Coordinating Center Data Safety Monitoring Board members: Anne Perkins, Knight Steel, George Taler, Stephanie Wilmer; Becky Clark for data management; Charles Rohde for advice on statistical methods; Curtis Meinert for advice on study design; Leslie Odendhal for coordinating center activities and manuscript preparation; Donna Regenstreif for her initial vision of the hospital at home; The John A. Hartford Foundation of New York for their ongoing support; Ronald Peterson for his support of hospital-athome development at Johns Hopkins; and the patients, family members, and caregivers who participated in the study.

Grant Support: By a grant from the John A. Hartford Foundation of New York, grant no. 98309-G, and supplemented by the Portland Oregon Veterans Administration Medical Center by a Department of Veterans Affairs New Clinical Initiative Program grant no. 99-027. Dr. Inouye was supported, in part, by grant no. K24AG00949 from the National Institute on Aging.

Potential Financial Conflicts of Interest: None disclosed.

Requests for Single Reprints: Bruce Leff, MD, John Hopkins Bayview Medical Center, The Johns Hopkins Care Center, John R. Burton Pavilion, 5505 Hopkins Bayview Circle, Baltimore, MD 21224; e-mail, bleff@jhmi.edu; Web site, www.hospitalathome.org.

Current author addresses and author contributions are available at www .annals.org.

\section{References}

1. Covinsky KE, Palmer RM, Fortinsky RH, Counsell SR, Stewart AL, Kresevic $\mathrm{D}$, et al. Loss of independence in activities of daily living in older adults hospitalized with medical illnesses: increased vulnerability with age. J Am Geriatr 
Soc. 2003;51:451-8. [PMID: 12657063]

2. Inouye SK, Bogardus ST Jr, Charpentier PA, Leo-Summers L, Acampora D, Holford TR, et al. A multicomponent intervention to prevent delirium in hospitalized older patients. N Engl J Med. 1999;340:669-76. [PMID: 10053175]

3. Creditor MC. Hazards of hospitalization of the elderly. Ann Intern Med. 1993;118:219-23. [PMID: 8417639]

4. Leff B, Burton JR. Acute medical care in the home [Editorial]. J Am Geriatr Soc. 1996;44:603-5. [PMID: 8617915]

5. Montalto M. Hospital in the Home: Principles and Practice. Melbourne: ArtWords Publishing; 2002.

6. Leff B. Acute? care at home. The health and cost effects of substituting home care for inpatient acute care: a review of the evidence. J Am Geriatr Soc. 2001; 49:1123-5. [PMID: 11555078]

7. Shepperd S, Iliffe S. Hospital at home versus in-patient hospital care. Cochrane Database Syst Rev. 2005(3):CD000356. [PMID: 16034853]

8. Ricauda NA, Bo M, Molaschi M, Massaia M, Salerno D, Amati D, et al. Home hospitalization service for acute uncomplicated first ischemic stroke in elderly patients: a randomized trial. J Am Geriatr Soc. 2004;52:278-83. [PMID: 14728641]

9. Davies L, Wilkinson M, Bonner S, Calverley PM, Angus RM. "Hospital at home" versus hospital care in patients with exacerbations of chronic obstructive pulmonary disease: prospective randomised controlled trial. BMJ. 2000;321: 1265-8. [PMID: 11082090]

10. Wilson A, Parker H, Wynn A, Jagger C, Spiers N, Jones J, et al. Randomised controlled trial of effectiveness of Leicester hospital at home scheme compared with hospital care. BMJ. 1999;319:1542-6. [PMID: 10591717]

11. Shepperd S, Harwood D, Jenkinson C, Gray A, Vessey M, Morgan P. Randomised controlled trial comparing hospital at home care with inpatient hospital care. I: three month follow up of health outcomes. BMJ. 1998;316: 1786-91. [PMID: 9624068]

12. Stessman J, Ginsberg G, Hammerman-Rozenberg R, Friedman R, Ronen D, Israeli A, et al. Decreased hospital utilization by older adults attributable to a home hospitalization program. J Am Geriatr Soc. 1996;44:591-8. [PMID: 8617912]

13. Caplan GA, Ward JA, Brennan NJ, Coconis J, Board N, Brown A. Hospital in the home: a randomised controlled trial. Med J Aust. 1999;170:156-60. [PMID: 10078179]

14. Montalto M, Dunt D. Home and hospital intravenous therapy for two acute infections: an early study. Aust N Z J Med. 1997;27:19-23. [PMID: 9079248] 15. Leff B, Burton L, Guido S, Greenough WB, Steinwachs D, Burton JR. Home hospital program: a pilot study. J Am Geriatr Soc. 1999;47:697-702. [PMID: 10366169]

16. Leff B, Burton L, Bynum JW, Harper M, Greenough WB, Steinwachs D, et al. Prospective evaluation of clinical criteria to select older persons with acute medical illness for care in a hypothetical home hospital. J Am Geriatr Soc. 1997; 45:1066-73. [PMID: 9288013]

17. Knaus WA, Draper EA, Wagner DP, Zimmerman JE. APACHE II: a severity of disease classification system. Crit Care Med. 1985;13:818-29. [PMID: 3928249]

18. Charlson ME, Pompei P, Ales KL, MacKenzie CR. A new method of classifying prognostic comorbidity in longitudinal studies: development and validation. J Chronic Dis. 1987;40:373-83. [PMID: 3558716]

19. Bach PB, Brown C, Gelfand SE, McCrory DC. Management of acute exacerbations of chronic obstructive pulmonary disease: a summary and appraisal of published evidence. Ann Intern Med. 2001;134:600-20. [PMID: 11281745] 20. Hunt SA, Baker DW, Chin MH, Cinquegrani MP, Feldman AM, Francis
GS, et al. ACC/AHA guidelines for the evaluation and management of chronic heart failure in the adult: executive summary. A report of the American College of Cardiology/American Heart Association Task Force on Practice Guidelines (Committee to revise the 1995 Guidelines for the Evaluation and Management of Heart Failure). J Am Coll Cardiol. 2001;38:2101-13. [PMID: 11738322]. 21. Niederman MS, Mandell LA, Anzueto A, Bass JB, Broughton WA, Campbell GD, et al. Guidelines for the management of adults with community-acquired pneumonia. Diagnosis, assessment of severity, antimicrobial therapy, and prevention. Am J Respir Crit Care Med. 2001;163:1730-54. [PMID: 11401897] 22. Katz S, Ford AB, Moskowitz RW, Jackson BA, Jaffe MW. Studies of illness in the aged. The index of ADL: a standardized measure of biological and psychosocial function. JAMA. 1963;185:914-9. [PMID: 14044222]

23. Lawton MP, Brody EM. Assessment of older people: self-maintaining and instrumental activities of daily living. Gerontologist. 1969;9:179-86. [PMID: 5349366].

24. Yesavage JA, Brink TL, Rose TL, Lum O, Huang V, Adey M, et al. Development and validation of a geriatric depression screening scale: a preliminary report. J Psychiatr Res. 1982;17:37-49. [PMID: 7183759]

25. Folstein MF, Folstein SE, McHugh PR. "Mini-mental state". A practical method for grading the cognitive state of patients for the clinician. J Psychiatr Res. 1975;12:189-98. [PMID: 1202204]

26. Cummings J. Clinical Neuropsychiatry. Vol. 9. Orlando: Grune \& Stratton; 1985.

27. Inouye SK, van Dyck CH, Alessi CA, Balkin S, Siegal AP, Horwitz RI. Clarifying confusion: the confusion assessment method. A new method for detection of delirium. Ann Intern Med. 1990;113:941-8. [PMID: 2240918]

28. Uhlmann RF, Larson EB, Buchner DM. Correlations of Mini-Mental State and modified Dementia Rating Scale to measures of transitional health status in dementia. J Gerontol. 1987;42:33-6. [PMID: 3794193]

29. Cole M, McCusker J, Dendukuri N, Han L. The prognostic significance of subsyndromal delirium in elderly medical inpatients. J Am Geriatr Soc. 2003;51: 754-60. [PMID: 12757560]

30. Picker Institute Hospital. Picker Institute Hospital Satisfaction Questionnaire. Boston, MA: Picker Institute Hospital; 1996.

31. Barber JA, Thompson SG. Analysis of cost data in randomized trials: an application of the non-parametric bootstrap. Stat Med. 2000;19:3219-36. [PMID: 11113956]

32. Leff B, Montalto M. Home hospital—-toward a tighter definition [Letter]. J Am Geriatr Soc. 2004;52:2141. [PMID: 15571559]

33. Ram FS, Wedzicha JA, Wright J, Greenstone M. Hospital at home for patients with acute exacerbations of chronic obstructive pulmonary disease: systematic review of evidence. BMJ. 2004;329:315. [PMID: 15242868].

34. Fried TR, van Doorn C, O'Leary JR, Tinetti ME, Drickamer MA. Older persons' perceptions of home and hospital as sites of treatment for acute illness. Am J Med. 1999;107:317-23. [PMID: 10527032]

35. Fried TR, van Doorn C, O'Leary JR, Tinetti ME, Drickamer MA. Older persons' preferences for home vs hospital care in the treatment of acute illness. Arch Intern Med. 2000;160:1501-6. [PMID: 10826465]

36. Inouye SK, Leo-Summers L, Zhang Y, Bogardus ST Jr, Leslie DL, Agostini JV. A chart-based method for identification of delirium: validation compared with interviewer ratings using the confusion assessment method. J Am Geriatr Soc. 2005;53:312-8. [PMID: 15673358]

37. Bridges CB, Harper SA, Fukuda K, Uyeki TM, Cox NJ, Singleton JA, et al. Prevention and control of influenza. Recommendations of the Advisory Committee on Immunization Practices (ACIP). MMWR Recomm Rep. 2003;52:134; quiz CE1-4. [PMID: 12755288] 


\section{Annals of Internal Medicine}

Current Author Addresses: Drs. Leff, Greenough, and Burton and Ms. Guido: Johns Hopkins Bayview Medical Center, The Johns Hopkins Care Center, John R. Burton Pavilion, 5505 Hopkins Bayview Circle, Baltimore, MD 21224.

Drs. Burton, Frick, and Steinwachs: Johns Hopkins University Bloomberg School of Public Health, Hampton House, 624 North Broadway, Baltimore, MD 21205.

Dr. Mader: P.O. Box 1035 (V-9-DIR), Portland Veterans Administration Medical Center, Portland, OR 97207.

Dr. Naughton: State University of New York, Buffalo, 100 High Street, Buffalo, NY 14203.

Dr. Burl: Fallon Clinic, 10 Chestnut Street, Worcester, MA 01609.

Dr. Inouye: Aging Brain Center, Institute for Aging Research, Hebrew Senior Life, 1200 Centre Street, Boston, MA 02131.

Dr. Langston: 125 Park Avenue, New York, NY 10017.

Author Contributions: Conception and design: B. Leff, L. Burton, B. Naughton, W.B. Greenough, S. Guido, C. Langston, K.D. Frick, D. Steinwachs, J.R. Burton.
Analysis and interpretation of the data: B. Leff, L. Burton, S.K. Inouye, C. Langston, K.D. Frick, D. Steinwachs, J.R. Burton.

Drafting of this article: B. Leff, L. Burton, B. Naughton, K.D. Frick. Critical revision of the article for important intellectual content: B. Leff, L. Burton, S.L. Mader, S.K. Inouye, W.B. Greenough, C. Langston, K.D. Frick, J.R. Burton.

Final approval of the article: B. Leff, L. Burton, B. Naughton, S.K. Inouye, W.B. Greenough, D. Steinwachs, J.R. Burton.

Provision of study materials or patients: S.L. Mader, B. Naughton, J. Burl, W.B. Greenough.

Obtaining of funding: B. Leff, L. Burton, S.L. Mader, B. Naughton, J. Burl, J.R. Burton.

Administrative, technical, or logistic support: B. Leff, L. Burton, B. Naughton, S.K. Inouye, J.R. Burton.

Collection and assembly of data: B. Leff, L. Burton, S.L. Mader, B. Naughton, J. Burl, S. Guido. 